\title{
Cultural Diversity, Intercultural Competence, Tolerance, and the Economy: A Review
}

\author{
O. ALHENDI ${ }^{1}$ \\ 1University of Debrecen, Faculty of Economics and Business, Ihrig Károly Doctoral School, \\ osama.alhendi@econ.unideb.hu
}

\begin{abstract}
Cultural diversity is generally a controversial topic in the literature. While some studies have proved that it provides economic benefits, others have denied this claim. However, the costs associated with this may be avoided by improving each of intercultural competency at the business level and social tolerance at the economy level. For this purpose, the study used a literature review analysis. Based on the literature, cultural diversity plays important role in enhancing innovation and entrepreneurship which are necessary for economic development. However, it may result in different challenges such as a lack of trust and conflict. Therefore, it could be feasible to manage and benefit from cultural diversity in the companies through cross-cultural training as well as cultural diversity management. On the other hand, economies can avoid cultural diversity's costs by adopting the policies and institutions which are necessary for enhancing the level of social tolerance among people.
\end{abstract}

Keywords: intercultural competence; tolerance; cultural diversity; and economic development

\section{Introduction}

According to Florida (2004), open, dynamic, and tolerant environments are more likely to be attractive for creative people. Hereby, this leads to economic dynamism and growth. In another sense, according to the economists, regional growth can be explained by human capital theory in which growth is not enhanced by minimizing the cost of doing business but through having highly educated and productive human capital [1]. However, this theory does not explain why human capital distribution varies from one place to another or why do creative people exist in certain places? In order to answer that, Florida $(2002,2005)$ developed what is called creative capital theory. Based on this theory, highly educated people are attracted to places having special features such as inclusiveness and diversity. Also, this category of people is well-known as the creative class, according to Florida, who is usually involved in knowledge-intensive industries [2][3]. For instance, the acceptance of Jews and other religious minorities, by countries such as Netherlands, the United Kingdom, and Sweden, attracted productive workforces and provided them with the possibility to be part of the economy, with positive impact [4][5]. Furthermore, it was revealed that special areas, such as London, Paris, New York, and Tokyo (e.g., global cities) grow economically due to innovation. The common feature of these cities is the level of cultural diversity they have reached [6].

In addition, Mokyr argued that diversity and tolerance are necessary requirements for innovation. According to the literature, significant attention has been paid to human capital and high-tech 
innovation in the last years. Regarding knowledge economy, talent, which can be considered as human as well as a creative capital, represents an important factor for the economy [3][7][8]. This explains why Silicon Valley is considered one of the most important locations in terms of talent, innovation as well as well-being in the world.

On the other hand, the spread of multinational corporations and the rise of international trade have taken place as a result of economic globalization. Besides that, globalization plays an important role in enhancing intercultural communication. Moreover, this, in turn, emphasizes the necessity of intercultural awareness which can be enhanced by understanding and training throughout the company [9]. This could help to benefit from cultural diversity and its role in team building, decision making, marketing as well as advertising. It is also important to mention here that it might be sufficient to gain a competitive advantage through certain products and their quality in the short run. However, it may also be obtained in the long run via the growth of professionalism and international knowledge [10]. Also, based on the literature, through training, it is possible to learn about other cultures and address problems resulted from culturally conflicting circumstances. Therefore, intercultural competence can be enhanced by accepting and respecting cultural diversity [11].

Based on the previous paragraphs, intercultural communication can be strengthened through increasing tolerance and intercultural competence. To demonstrate this, Vosviewer software was used to visualize and analyse bibliometric networks of previous studies. In this study, the network consists of 67 studies related to tolerance and intercultural competence. As shown in Figure 1, there is an association between each of intercultural competence, tolerance, and intercultural communication. Besides that, the network shows that tolerance is linked with intercultural competence as a subcomponent. Hereby, intercultural competence can be considered as a general important concept which is also linked to other various topics such as multiculturalism, cultural competency, ethno-linguistic and didactic attribution, etc.

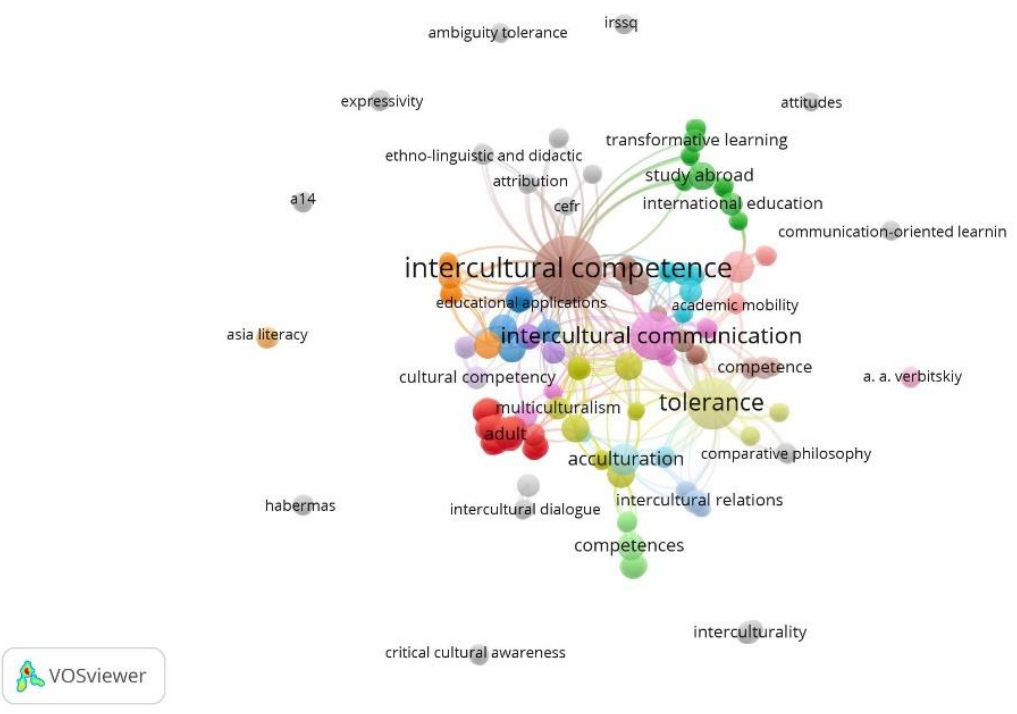

Figure 1. Intercultural Competence and Tolerance

Source: Author's own compilation (2021). 
Furthermore, as observation, it might be argued that tolerance was considered, by the literature, at the level of nations. While intercultural competence was taken into the account at the level of firms. However, there are many questions requiring answer such as: how tolerance and intercultural competence are related to each other? and how does both of them help to enhance the economic performance? Hereby, this study contributes to the existing literature on intercultural communication and the economy in different ways. First, it helps to provide a complete picture of how intercultural communication, through intercultural competence and tolerance, can enhance economic performance. Secondly, using literature review analysis, the study also includes critiques in order to make the study more objective.

Finally, the study used literature review analysis with the aim to investigate whether tolerance and intercultural competence enhance economic development or not. Therefore, the literature review section consists of four subsections as the following. The first subsection defines and clarifies the relationship between tolerance and intercultural competence. The second and third subsections discuss the impact of intercultural competence and tolerance on the micro as well as macro-economic levels. The fourth subsection includes critiques of other previous studies related to this topic. The last section concludes the study.

\section{Literature Review}

\subsection{Intercultural Competence and Tolerance}

Based on the literature, intercultural communicative competence gained the attention of researchers in the early 1950s. However, the first comprehensive approaches were created in the late 1970s. For example, one of these approaches was the behavioural approach, which was developed by Brent D. Ruben who argued that one of the most difficult obstacles is the matter of how to practically implement our knowledge related to other cultures [12]. Furthermore, as reported by Ruben (1976), intercultural competence can be measured through seven dimensions. The first dimension is the display of respect in which individuals should have the ability to convey a positive consideration to others. This may include eye contact, voice tone, etc. The second dimension is called interaction posture. This dimension reflects the ability of people to be neutral while they are communicating with foreign cultures. The third one is the orientation to knowledge in which individuals should have the capacity to acknowledge other's kind of knowledge. Empathy, the fourth one, represents an individual's ability to understand other's perspectives. Regarding the fifth dimension, self-oriented role behaviour, it is related to people's ability to adapt and participate in different roles in the groups they belong to. The next dimension is called interaction management in which the individual should be able to join discussions, start and end the interactions which take place based on other's needs and desires. The last dimension is tolerance for ambiguity which indicates the ability of people to adapt and accommodate to new and ambiguous situations. Hereby, the higher the scale of each dimension, the higher people's perceiving of various cultures, values, and behaviours [13]. Also, it is possible to define intercultural competence as "the ability to communicate effectively in cross-cultural situations and to relate appropriately in a variety of cultural contexts" [14]. 
In contrast, tolerance is defined as an attitude of being open-minded and respectful toward diversity, regardless of people's ethnic, social backgrounds, or lifestyle they have preferred [15]. To some degree, this definition matches other researchers' work such as Persell et al. (2001), Gibson (1992); Gibson and Tedin (1988); Ostheimerand Ritt (1982) [16][17][18][19]. Therefore, tolerance can be estimated using variables that represent a person's attitudes toward others who are belonging to various social groups. For example, according to Persell et al. (2001), tolerance toward African Americans and homosexuals can be considered as a measurement to estimate society's social tolerance. Based on their study, tolerance toward African Americans can be evaluated or represented by "the willingness (by whites) to invite a black person to dinner, to support interracial marriage, and to vote for a black president." Regarding homosexuals, Persell et al. argued that tolerance toward homosexuals can be estimated by the extent to which people are supportive of homosexual's civil rights. In addition, Florida (2003) adopted three measures, to estimate the level of tolerance or diversity, like the following. The first measurement is called Gay index which indicates the rate of the gay and lesbian community. The second one is the Bohemian Index (i.e., the rate of the artistic population). The last index is the Melting Pot Index, which indicates the rate of immigrant people [20]. Furthermore, Florida (2008) created another index called Tolerance Index in which Gay Index and the Bohemian Index are combined [21].

After defining and explaining how intercultural competence and tolerance can be measured, it is important to shed the light here on how both of them are related to each other. In fact, in the context of intercultural communication, tolerance toward diversity has been taken into consideration in connection with intercultural competence. Also, enhancing intercultural competence leads people to be tolerant of differences. For example, communication behaviour is explained in the context of social capital, as specified by sociology. Depending on the literature, Coleman (1990) argued that social capital exists essentially in the structure of relations between people. Furthermore, mutual trust is considered an important factor that helps to ease social interactions [22]. Also, Putnam et al. (1994) highlight the importance of civic community and its role in enhancing regional networks [23]. However, tolerance toward diversity has not been given enough attention in the field of urban economics in comparison with intercultural communication and sociology. For instance, some researchers studied the linkage between tolerance toward diversity and other factors such as the structure of communication and the social network [24][25], the creation and transfer of knowledge [26], and how communication enhances the existence of multicultural cities [27].

In addition, it can be argued that people have exercised intercultural competence when one of the communication parties chooses to be highly tolerant, even though the other party has, relatively, low level of tolerance. In this case, mutual openness will be higher. Besides that, according to Ihara and Yamamoto (2016), tolerance can be interpreted through intercultural sensitivity level, which is considered as one of the important theories in intercultural competence. Hereby, a lower level of tolerance is equivalent to a lower level of intercultural sensitivity. According to the developmental model of intercultural sensitivity, the lower level is called ethnocentrism, which includes each of denial, defense, and minimization stages, in which individuals assess other cultures based on their own values and beliefs. On the other hand, a high level of tolerance equals a high level of intercultural sensitivity. This stage is well-known as ethnorelativism, including acceptance, adaptation, and 
integration stages, which indicates people's ability to see other's values and behaviors as cultural rather than universal. Consequently, it is possible to conclude that having a high level of tolerance leads to a high level of intercultural sensitivity which helps the individuals to be able to practice intercultural competence. Furthermore, enhancing the level of tolerance can be achieved through education and training of intercultural knowledge [28].

\subsection{The impact of intercultural competence and tolerance on the micro and macro-economic level}

\subsubsection{On the Micro-economic level}

Based on the literature, most of the studies investigate the role of intercultural communication in enhancing the performance of the firms through evaluating and developing the intercultural competence and tolerance level of employees. For example, in order to ensure the success of a certain company, it is necessary to turn cultural diversity problems into advantages. This can be achieved through the management of cultural diversity by which diversity is deemed as a valuable resource yielding economic benefit and creating a competitive advantage to the firms. In fact, the reason behind the importance of cultural diversity management is attributed to its role in ensuring equal opportunities among people having cultural differences [29][30]. In the other words, it is possible to conclude that cultural diversity management helps to enhance tolerance toward differences among employees and provide them special value or status [31]

Based on that, organizations are categorized, in terms of their organizational culture, into two types. The first type believes that having a homogeneous workplace, unified rules, and common values, is necessary to last and survive in the market. However, the company may risk losing its competitive advantage due to the lack of sufficient tolerance of its employees and its capability to adapt to new circumstances in the dynamic environment. On the other hand, the second type believes that the creativity of employees, innovations, effective problem solving, and customer orientations can be enhanced and achieved through having a high level of tolerance toward differences in the workplace. Hereby, this type of company considers diversity as a valuable resource which is important for their success [32].

In fact, the performance of the companies is enhanced through the role of teams. Also, teams, within companies, are categorized into different types. For example, generally, the real team is defined as a small group of individuals having complementary expertise, such as technical, interpersonal, and problem-solving skills. The members of the team are equally obliged to work and achieve a common purpose or aim for which they are mutually responsible. Another type of team is called highperformance teams. This type considerably performs better than average teams since high-performance team members are highly committed to success. Comparing to the first type, the second one has deeper sense of purpose, a thorough approach for problem solving, and full mutual responsibility among team members [33]. The third type is called multicultural team which includes a group of people with various nationalities and cultures. Also, they are characterized as a task-oriented group. Hereby, in this case, high-performance multicultural teams are defined as multicultural teams with two important characteristics. Firstly, they are similar to high-performance teams in terms of the previously mentioned 
features. Secondly, these teams consist of people having diverse nationalities and cultures. Therefore, having a team of managers from different cultures results in several points of view as well as many creative methods which are necessary to solve the related challenges [34]. Furthermore, multicultural teams play a significant part in increasing the level of a company's productivity [35]. Also, the lack of a multicultural team's effectiveness could cause the resources of the company to run out. This could happen due to the impact of cultural diversity which may result in conflict, misunderstanding, and weak performance [36]. Consequently, according to the study of Matveev and Milter (2004), about 96 percent of managers emphasized the significance of intercultural competence and its role in enhancing the effectiveness of multicultural teams within multinational entities [37].

Moreover, continuity of strategic alliances and international ventures is highly influenced by the degree of cultural differences which global partners have [38]. Besides that, intercultural competence is an important factor, nowadays, for the global workplace since it influences global leadership effectiveness [39].

Finally, intercultural competence is heavily required by organizations because of the following. For instance, the level of innovation in a certain organization is associated with the extent to which diversity takes place [40]. This can be justified because heterogeneity within a group of people or teams is linked with the amount of experiences they possess [41]. Therefore, cross cultural training is important for organizations where employees are working in a multicultural workplace. This type of training helps to transform employees from being ethnocentric into culturally relative. In other words, cross cultural training renders people more adaptable through teaching them global skills which are crucial for specific circumstances [42].

\subsubsection{On the Macro-economic level}

In the previous section, the impact of intercultural communication was discussed on the level of companies and organizations and mostly is related to the term of intercultural competence. However, in this section, on the macroeconomic level, tolerance is mostly used, in the literature, instead of intercultural competence. For example, literature gave more attention to social tolerance and economic development during the last decade [43][44]. Furthermore, it has been argued that the level of tolerance is associated with many different implications such as economic performance [45], the growth of population [46] as well as social development [47]. Besides that, according to Florida (2014) tolerance toward others results in a highly dynamic economy, where he argues that:

"The more tolerant a place is, the more welcoming it is to all kinds of people, and the more likely it is to attract the kinds of people who are oriented towards selfexpression and openness to experience - which psychological studies show are key characteristics of entrepreneurial behavior" [48].

Social tolerance thus has an essential role to play in improving economic performance. This can be justified by the following reasons. Firstly, social tolerance helps to enhance each individual autonomy and diversity. This, in turn, encourages a variety of ideas, competition, and the level of creative entrepreneurship [49]. Secondly, the structure of tolerant societies is open and hence new ideas and knowledge can overflow easily [50]. Thirdly, skilled labor is usually attracted to places that are highly tolerant. Therefore, this leads to the achievement of a high degree of innovation and entrepreneurship 
in these regions [48]. On the other hand, the lack of people's tolerant attitude toward diversity prevents and hinders the free movement of talent [51], and prefers corruption and political backing [52].

As previously explained, it can be clear that diversity requires tolerance. Hereby, the economy can benefit from cultural diversity through adopting policies and rules which enhance the level of society's tolerance toward differences. The economic benefit of diversity can be explained through a cycle of different aspects discussed as the following. As generally known, companies usually tend to collect and gather necessary information from their clients in order to improve the current product or develop a new one [53]. This procedure indicates what is called the demand pull innovation theory which is proposed by Jacob (1966) [54]. Hereby, having a diverse society results in heterogeneous preferences [55], and even in consumption as in the case of Netherlands [56]. As a result, preference heterogeneity, for products and services, enhances the entry of startups related to technology. On the other hand, the firms, which already exist, do their best to compete with the new ones by proceeding with their innovative activities [57]. In addition, based on the studies of Aghion and Howitt (1992); Grossman and Help-man (1991), knowledge is considered an important determinant of productivity [58][59]. Therefore, as argued by Alesina and Ferrara (2005), cultural diversity increases productivity through attracting expertise and knowledge [60]. For example, educated and skilled immigrants are usually attracted to tolerant environments where diversity exists as in the case of Germany where knowledge may include each of work structure, support of external contacts, communication, and creativity [61].

Consequently, in order to manage diversity, it is critical to adopt policies that enhance social tolerance in the economy. Having a high degree of tolerance attracts the skills and knowledge required for innovation and economic growth.

\subsection{Critiques}

In fact, the literature argues that the link between tolerance and economic growth is still unclear [62][63]. Furthermore, despite the economic importance of intercultural communication on the macro and microeconomic levels, there are also related costs. For instance, Niebuhr (2010) proved that the diversity's benefits, such as idea pluralism, open-mindedness, and creativity, exceed its costs, such as communication and coordination. This may hinder the process of innovation activity [64]. In addition, contrary to the findings of Florida, Putnam (2007) found out that diversity decreases social capital. In other words, it causes a decline in the number of people's participation in civic activities as well as the level of trust between and within ethnic groups in the economy [65]. These findings are also supported by others such as Alesina and Ferrara (2005); Alesina and Glaeser (2004); McPherson et al. (2006) [60][66][67]. However, these findings were criticized by a number of researchers from different fields such as Bearman and Parigi (2004); Costa and Kahn (2003); Paxton (1999), etc [68][69][70]. Another study by Pool (1972) revealed that linguistic diversity and economic growth are negatively related. He argued that linguistic fragmentation results in social breakdown, conflict and, corruption which could negatively influence economic growth [71].

Furthermore, Berggren and Elinder (2012) found out that economies with intolerant societies, on average, demonstrate stronger economic development. Besides that, they argued that skilled people who are sexually biased would avoid moving to tolerant environments since these places are tolerant toward homosexuality and this could decrease their productivity [49]. 
On the other hand, Sparber (2009) claimed that diversity, especially racial diversity, has a positive and negative impact on the economy. Whereas racial diversity positively influences wages in specific sectors (such as legal services, computer manufacturing, and software), it has a negative impact on the wages in the traditional sectors in the United States. Hereby, these findings propose that the impact of workforce diversity may differ according to the economic circumstances such as the category of industries, production as well as income levels [72]. Furthermore, according to the study of Horwitz and Horwitz (2007), cultural diversity may result in linguistic diversity and a lack of trust. Consequently, this could lead to significant challenges such as transaction costs and conflicting divisions [73]. Besides that, Ozgen et al. (2013) analysed data from 4000 firms in the Netherlands and discovered that the greater the quota of foreign employees, the greater the negative effect on the company's capacity to innovate [74].

\section{Conclusion}

Based on the previous discussion, there is no doubt regarding the economic benefits of cultural diversity on the macro and microeconomic levels. However, it is important to avoid the costs resulted from diversity. As previously explained, it is possible to benefit from and manage cultural diversity through each of intercultural competence as well as tolerance. These two concepts are related to each other since intercultural competence helps to render people tolerant toward differences.

On the level of companies, cultural diversity is usually associated with productivity, as in the case of multicultural teams role in the firm [35] and innovation [40]. However, other studies related diversity to different challenges such as lack of trust and conflict [73]. On the other hand, on the level of economies, tolerance toward cultural diversity results in a high degree of innovation and entrepreneurship [48]. In contrast, others, such as Pool (1972), attributed each of conflict and corruption to cultural diversity [71]. Also, Putnam (2007) argued that diversity results in a lack of trust between and within groups in the society [65].

Consequently, based on the literature, companies usually benefit from cultural diversity and avoid its costs through cultural diversity management as well as cross cultural training (which are necessary to increase the level of intercultural competence among employees). On the level of economies, this can be achieved through developing policies and rules which help to increase the level of social tolerance among people.

\section{References}

[1] Florida, R., 2004. Revenge of the squelchers. The Next American City, Volume 5.

[2] Florida, R., 2002. The economic geography of talent. Annals of the Association of American geographers, Volume 92, p. 743-755.

[3] Florida, R., 2005. Cities and the Creative Class. s.l.:Routledge.

[4] Mokyr, J., 1990. The Lever of Riches: Technological Creativity and Economic Progress. s.l.:Oxford University Press. 
[5] Grell, 0. P., Porter, R. \& others, 2000. Toleration in enlightenment Europe. s.l.:Cambridge University Press.

[6] Sassen, S., 1994. Cities in a world economy. s.l.:Thousand Oaks, CA: Pine Forge Press.

[7] Lucas, R., 1988. On the mechanics of economic development. Journal of Monetary Economics, Volume 22, p. 3-42.

[8] Garnett, B., Guppy, N. \& Veenstra, G., 2008. Careers Open to Talent: Educational Credentials, Cultural Talent, and Skilled Employment. s.l., s.n., p. 144-164.

[9] Sorrells, K., 2013. Intercultural Communication. Globalization and Social Justice. s.l.:California State University, Northridge.

[10] Kusa, R., 2004. Kompetencje kierownicze jako źródło przewagi konkurencyjnej w małych przedsiębiorstwach usługowych,[in:] Nowoczesność przemysłu i usług. Nowe wyzwania, red. J. Pyka, Volume 2.

[11] Mandenhal, M. \& Oddou, G., 1995. The dimensions of expatriate acculturation: a Review. In Jackson, T. (ed) Cross-cultural Management. Butterworth-Heinemann, Oxford.

[12] Ruben, B. D. \& Kealey, D. J., 1979. Behavioral assessment of communication competency and the prediction of cross-cultural adaptation. International Journal of Intercultural Relations, Volume 3, p. 15-47.

[13] Ruben, B. D., 1976. Assessing communication competency for intercultural adaptation. Group \& Organization Studies, Volume 1, p. 334-354.

[14] Bennett, J. M. \& Bennett, M. J., 2004. Developing intercultural sensitivity: An integrative approach to global and domestic diversity, [in:] Handbook of intercultural training, eds. D. Landis, J.M. Bennett, M.J. Bennett. s.l.:Sage Publications, Thousand Oaks, CA.

[15] Florida, R., 2003. Entrepreneurship, creativity, and regional economic growth. The emergence of entrepreneurship policy, p. 39-58.

[16] Persell, C. H., Green, A. \& Gurevich, L., 2001. Civil society, economic distress, and social tolerance. s.l., s.n., p. 203-230.

[17] Gibson, J. L., 1992. The political consequences of intolerance: Cultural conformity and political freedom. The American Political Science Review, p. 338-356.

[18] Gibson, J. L. \& Tedin, K. L., 1988. The etiology of intolerance of homosexual politics. Social Science Quarterly, Volume 69, p. 587-604.

[19] Ostheimer, J. M. \& Ritt, L. G., 1982. Abundance and American democracy: a test of dire predictions. The Journal of Politics, Volume 44, p. 365-387.

[20] Florida, R., 2003. Cities and the creative class. City \& community, Volume 2, p. 3-19.

[21] Florida, R., Mellander, C. \& Stolarick, K., 2008. Inside the black box of regional developmenthuman capital, the creative class and tolerance. Journal of economic geography, Volume 8, p. 615649. 
[22] Coleman, J. S., 1990. Foundations of Social Theory. Harvard University Press, Cambridge.

[23] Putnam, R. D., Leonardi, R. \& Nanetti, R. Y., 1994. Making Democracy Work: Civic Traditions in Modern Italy. In: Making Democracy Work. s.l.:Princeton University Press.

[24] Jackson, M. O. \& Wolinsky, A., 1996. A strategic model of social and economic networks. Journal of economic theory, Volume 71, p. 44-74.

[25] Jackson, M. O., 2008. Social and economic networks. s.l.:Princeton university press, Princeton.

[26] Berliant, M. \& Fujita, M., 2008. Knowledge creation as a square dance on the Hilbert cube. International Economic Review, Volume 49, p. 1251-1295.

[27] Ottaviano, G. I. P. \& Prarolo, G., 2009. Cultural identity and knowledge creation in cosmopolitan cities. Journal of Regional Science, Volume 49, p. 647-662.

[28] Ihara, R. \& Yamamoto, S., 2016. Role of tolerance in communication with diverse people. The Annals of Regional Science, Volume 56, p. 191-202.

[29] Krislin, C. \& Köppel, P., 2008. Diversity Management durch die Hintertür: über das wirtschaftliche Potenzial von kultureller Vielfalt im Mittelstand. s.l.:Bertelsmann-Stiftung.

[30] Thomas, D. A. \& Ely, R. J., 1996. Making differences matter: A new paradigm for managing diversity. Harvard business review, Volume 74, p. 79.

[31] Süß, S. \& Kleiner, M., 2005. Diversity-Management in Deutschland: Ergebnisse einer Unternehmensbefragung. Fernuniversität in Hagen, Fachbereich Wirtschaftswissenschaft, Arbeitsbericht.

[32] Köppel, P., Yan, J. \& Lüdicke, J., 2007. Cultural diversity management in Deutschland hinkt hinterher. s.l.:Bertelsmann-Stiftung Gütersloh.

[33] Katzenbach, J. R. \& Smith, D. K., 1999. The wisdom of teams: Creating the high-performance organization. s.l.:Harper Collins Publishers, New York, NY.

[34] Marquard, M. J. \& Horvath, L., 2001. Global teams. How Top Multinationals Span Boundaries and Cultures with High-speed Teamwork, Davies-Black Publishing, Palo Alto, CA.

[35] Townsend, A. M., DeMarie, S. M. \& Hendrickson, A. R., 1998. Virtual Teams: Technology and the Workplace of the Future. The Academy of Management Executive (1993-2005), Volume 12, p. 1729.

[36] Shenkar, 0. \& Zeira, Y., 1992. Role conflict and role ambiguity of chief executive officers in international joint ventures. Journal of international business studies, Volume 23, p. 55-75.

[37] Matveev, A. V. \& Milter, R. G., 2004. The value of intercultural competence for performance of multicultural teams. Team Performance Management: An International Journal.

[38] Rodríguez, C. M., 2005. Emergence of a third culture: shared leadership in international strategic alliances. International Marketing Review, Volume 22, p. 67-95. 
[39] Bird, A., Mendenhall, M., Stevens, M. J. \& Oddou, G., 2010. Defining the content domain of intercultural competence for global leaders. Journal of Managerial Psychology, Volume 25, p. 810828.

[40] Yang, Y. \& Konrad, A. M., 2011. Diversity and organizational innovation: The role of employee involvement. Journal of Organizational Behavior, Volume 32, p. 1062-1083.

[41] Hoogendoorn, S. \& van Praag, M., 2012. Ethnic diversity and team performance: a field experiment. Tinbergen Institute Discussion Paper.

[42] Littrell, L. N. \& Salas, E., 2005. A review of cross-cultural training: Best practices, guidelines, and research needs. Human Resource Development Review, Volume 4, p. 305-334.

[43] Akerlof, G. A. \& Kranton, R. E., 2000. Economics and identity. The quarterly journal of economics, Volume 115, p. 715-753.

[44] Shi, Y. \& Peng, D., 2014. Dynamics of social tolerance in the economic interaction model with three groups. Applied Economics Letters, Volume 21, p. 665-670.

[45] Berggren, N. \& Nilsson, T., 2013. Does economic freedom foster tolerance?. Kyklos, Volume 66, p. 177-207.

[46] Becchetti, L., Rossetti, F. \& Castriota, S., 2010. Real household income and attitude toward immigrants: an empirical analysis. The Journal of Socio-Economics, Volume 39, p. 81-88.

[47] Bjørnskov, C., 2004. Inequality, Tolerance, and Growth, s.l.: s.n.

[48] Florida, R., 2014. The creative class and economic development. Economic development quarterly, Volume 28, p. 196-205.

[49] Berggren, N. \& Elinder, M., 2012. Is tolerance good or bad for growth?. Public Choice, Volume 150, p. 283-308.

[50] Hauser, C., Tappeiner, G. \& Walde, J., 2007. The learning region: the impact of social capital and weak ties on innovation. Regional studies, Volume 41, p. 75-88.

[51] Florida, R., 2006. The flight of the creative class: The new global competition for talent.. Liberal Education, Volume 92, p. 22-29.

[52] Tabellini, G., 2010. Culture and institutions: economic development in the regions of Europe. Journal of the European Economic association, Volume 8, p. 677-716.

[53] Jovanovic, B. \& Rob, R., 1987. Demand-driven innovation and spatial competition over time. The Review of Economic Studies, Volume 54, p. 63-72.

[54] Jacob, S., 1966. Invention and economic growth. J. Schmookler.-Cambridge Mass: Harvard University Press.

[55] Alesina, A., Spolaore, E. \& Wacziarg, R., 2005. Trade, growth and the size of countries. In: Handbook of economic growth. s.l.:Elsevier, p. 1499-1542.

[56] Bakens, J., Mulder, P. \& Nijkamp, P., 2013. Economic impacts of cultural diversity in the Netherlands: Productivity, utility, and sorting. Journal of Regional Science, Volume 53, p. 8-36. 
[57] Aghion, P. et al., 2009. The Effects of Entry on Incumbent Innovation and Productivity. The Review of Economics and Statistics, 2, Volume 91, pp. 20-32.

[58] Aghion, P. \& Howitt, P., 1992. A Model of Growth Through Creative Destruction. Econometrica: Journal of the Econometric Society, p. 323-351.

[59] Grossman, G. M. \& Helpman, E., 1991. Innovation and growth in the global economy. s.l.:MIT press.

[60] Alesina, A. \& Ferrara, E. L., 2005. Ethnic diversity and economic performance. Journal of economic literature, Volume 43, p. 762-800.

[61] Bouncken, R. B., 2004. Cultural diversity in entrepreneurial teams: Findings of new ventures in Germany. Creativity and Innovation Management, Volume 13, p. 240-253.

[62] Donegan, M. et al., 2008. Which indicators explain metropolitan economic performance best? Traditional or creative class. Journal of the American Planning Association, Volume 74, p. 180195.

[63] Storper, M. \& Scott, A. J., 2009. Rethinking human capital, creativity and urban growth. Journal of economic geography, Volume 9, p. 147-167.

[64] Niebuhr, A., 2010. Migration and innovation: Does cultural diversity matter for regional R\&D activity?. Papers in Regional Science, Volume 89, p. 563-585.

[65] Putnam, R. D., 2007. E pluribus unum: Diversity and community in the twenty-first century the 2006 Johan Skytte Prize Lecture. Scandinavian political studies, Volume 30, p. 137-174.

[66] Alesina, A. \& Glaeser, E., 2004. Fighting Poverty in the US and Europe: A World of Difference. Oxford UK: Oxford University Press.

[67] McPherson, M., Smith-Lovin, L. \& Brashears, M. E., 2006. Social isolation in America: Changes in core discussion networks over two decades. American sociological review, Volume 71, p. 353375.

[68] Bearman, P. \& Parigi, P., 2004. Cloning headless frogs and other important matters: Conversation topics and network structure. Social Forces, Volume 83, p. 535-557.

[69] Costa, D. L. \& Kahn, M. E., 2003. Understanding the American decline in social capital, 1952-1998. Kyklos, Volume 56, p. 17-46.

[70] Paxton, P., 1999. Is social capital declining in the United States? A multiple indicator assessment. American Journal of sociology, Volume 105, p. 88-127.

[71] Pool, J., 1972. National development and language diversity. s.l., The Hague: Mouton, p. 213-230.

[72] Sparber, C., 2009. Racial diversity and aggregate productivity in US industries: 1980-2000. Southern Economic Journal, p. 829-856.

[73] Horwitz, S. K. \& Horwitz, I. B., 2007. The effects of team diversity on team outcomes: A metaanalytic review of team demography. Journal of management, Volume 33, p. 987-1015.

[74] Ozgen, C., Nijkamp, P. \& Poot, J., 2013. The impact of cultural diversity on firm innovation: evidence from Dutch micro-data. iza Journal of Migration, Volume 2, p. 1-24. 